\title{
O emocionar e o saber ser professor de um coletivo de fisioterapeutas
}

\author{
Exciting and knowing how to be a teacher of a group of physiotherapists
}

Emocionante y saber ser profesor de un grupo de fisioterapeutas

\begin{abstract}
Roberta Tavares Thomé ${ }^{1 *}$, Renata da Silva Peixoto ${ }^{1}$, Débora Pereira Laurino ${ }^{1}$, Sheyla Costa Rodrigues ${ }^{1}$.
\end{abstract}

\section{RESUMO}

Objetivo: Conhecer como os profissionais de Fisioterapia, transformam o conteúdo específico de sua área de conhecimento em conhecimento de ensino. Métodos: Estudo qualitativo realizado com dez professores graduados em Fisioterapia que atuam na sala de aula de uma Instituição de Ensino Superior (IES). A opção pelo conversar individual foi o método que nos pareceu adequado para o Estudo e envolveu perguntas com temas como o tempo de trabalho, a formação acadêmica e a decisão pela docência, práticas e técnicas utilizadas em sala de aula, recursos e avaliações do desempenho dos alunos que poderiam nos auxiliar a compreender o problema do estudo. A análise do conversar foi realizada pela técnica do Discurso do Sujeito Coletivo. Resultados: Formou os discursos coletivos que denominamos: DSC1 - O emocionar da docência; DSC2 - A prática da docência. O sujeito fisioterapeuta, pelas interações recorrentes foi sendo constituído na rede de conversação docente e, na convivência, foi se transformando no fazer e no emocionar da docência. Conclusão: Pelos atravessamentos com o fazer docente em sua trajetória de vida e pelas próprias experiências da ação, esses profissionais se produzem na docência na condição de sabedores de um conhecimento específico e de uma emoção que lhes move a fazer o que fazem.

Palavras-chave: Fisioterapia, Docentes, Conhecimento.

\begin{abstract}
Objective: To know how the physical therapists professionals transform the specific content of their label area of knowledge in teaching knowledge. Methods: Qualitative study carried out with ten professors graduated in Physiotherapy who work in the classroom of a Higher Education Institution (HEI). The option of the individual conversation was the method that seemed appropriate method for this study because we could reach more subjects as the work time, their academic formation and the how they made a decision about teaching, practices and techniques used in class, resources and the students' evaluations performances that could help us about the comprehension of the study's problem. The conversation analysis was performed using the collective subject discourse technique. Results: Formed the collective speeches that were denominated: DSC1 - The emotional part about teaching; DSC2 - The teaching practice. The subject physiotherapist, by the recurrent interactions was been built in the teaching's conversation field and in the coexistence and was built by the act of doing and the teaching's emotional experience. Conclusion: Through the crossings with the teaching profession in their life trajectory and the very experiences of the action, these professionals are produced in teaching in the condition of knowing a specific knowledge and an emotion that moves them to do what they do.
\end{abstract}

Key words: Physiotherapy, Teaching, Knowledge.

\footnotetext{
1 Universidade Federal do Rio Grande (FURG), Rio Grande - RS.
}

*E-mail: peixoto@vetorial.net

SUBMETIDO EM: 2/2020

ACEITO EM: 3/2020

PUBLICADO EM: 5/2020

REAS/EJCH | Vol.12(6) | e3219 | DOI: https://doi.org/10.25248/reas.e3219.2020 Página 1 de 7 


\section{RESUMEN}

Objetivo: Conocer como los profesionales de kinesiología, transforman el contenido específico de su área de conocimiento en conocimiento de enseñanza. Métodos: Estudio cuolitativo realizado con diez profesores recibidos en fisioterapia que trabajan en clase de una institución de enseño superior (IES). La opción para la conversación individual era el método que parecía apropiado para el estudio y envolvió temas como el tiempo de laburo, la formación de graduación y la decisión por la docencia, prácticas y técnicas utilizadas en clase, recursos y evaluaciones del rendimiento de los estudiantes que nos pudieron ayudar en la comprensión del problema del estudio. El análisis de la conversación se realizó utilizando la técnica del discurso del sujeto colectivo. Resultados: Formado los discursos colectivos que hemos elegido: DSC1 - El emocionar da docencia; DSC2 - La práctica de la docencia. El sujeto fisioterapeuta, por las interacciones recurrentes fue constituyéndose en la red de conversación docente y en la convivencia, fue transformándose en el hacer y en el emocionar de la docencia. Conclusión: A través de los cruces con la profesión docente en su trayectoria de vida y las propias experiencias de la acción, estos profesionales se producen en la enseñanza con la condición de conocer un conocimiento específico y una emoción que los mueve a hacer lo que hacen.

Palabras clave: Fisioterapia, Docentes, Conocimiento.

\section{INTRODUÇÃO}

Pensar, refletir e inquietar-se com um problema são ações cotidianas que movem e perturbam a todos nós, observadores que somos, pois permeiam o viver na experiência de quem problematiza. Para compreender os conhecimentos mobilizados durante a prática pedagógica de profissionais da fisioterapia no exercício da docência é preciso dar voz a esse coletivo imbricado com a formação profissional dos estudantes (MATURANA H, 2001).

O observar, para Maturana $\mathrm{H}$ (2002), é o que nós, observadores, fazemos ao distinguir na linguagem os diferentes tipos de entidades que trazemos à mão como objetos de nossas descrições, explicações e reflexões no curso de nossa participação nas diferentes redes de conversações em que estamos envolvidos em nossas vidas cotidianas, independentemente do domínio operacional em que acontecem. Assim, não existe separação entre produtor e produto o que valida o aforismo "Todo fazer é conhecer e todo conhecer é fazer" (MATURANA H, 2002).

Se não existe separação entre quem conhece de quem faz, podemos dizer que sabemos o que é ser professor mesmo que não tenhamos uma formação específica para tal, pois as nossas experiências, na condição de estudantes, nos fazem construir um conjunto de ideias que nos permitem dizer ou, até mesmo, fazer a docência (TARDIF M, 2003).

Para construir um explicar sobre as nossas perturbações e inquietações sobre a docência de fisioterapeutas professores recorremos aos autores Humberto Maturana, Francisco Varela, Maurice Tardif e Lee Shulman como aportes necessários para validar os caminhos escolhidos. Nesse artigo, nossa explicação envolve o entendimento de como os fisioterapeutas professores mobilizam seus conhecimentos pedagógicos para exercer a docência, se pensarmos que no âmbito de sua formação inicial não existem componentes curriculares que os preparem para tal (ALMEIDA MI, et al., 2019). Como aponta Backes VMS, et al. (2017), a intercessão entre o conteúdo e o conhecimento pedagógico, está na capacidade do professor em transformar e apresentar seu conhecimento da matéria em maneiras didaticamente impactantes e, ainda assim, adaptáveis as especificidades, habilidades e bagagens que apresentam seus alunos.Como observadores, tivemos a oportunidade de participar de redes de conversações que nos moveram na paixão de explicar o que fazem e como fazem esses profissionais quando assumem a docência como atividade profissional.

Nesse trabalho, assumimos a perspectiva das explicações científicas propostas por Maturana $H,(2001)$, sem desconsiderar que podem existir tantos explicares quanto observadores que os explicam. Para o autor, 
a ciência é uma atividade humana e tem validade e significado apenas no contexto da coexistência a qual surge. Entendemos que a ciência acontece a partir de um domínio de ação fundamental na emoção, que é a curiosidade, sob forma do desejo ou paixão pelo explicar.

Dessa forma, ao perceber a necessidade de compreender os desafios dos professores fisioterapeutas que não foram preparados para o fazer docente em sua formação e que se produzem professores no estar professor justificamos esse estudo. Para compreender o que e como fazem e o que dizem seus discursos, entendemos ser necessário entrelaçar conceitos para elucidar o problema que norteia o presente artigo. $O$ objetivo principal do estudo foi conhecer como os profissionais de Fisioterapia transformam o conteúdo específico de sua área de conhecimento em conhecimento de ensino.

\section{MÉTODOS}

A pesquisa trata-se de um estudo qualitativo. Para conhecer como os fisioterapeutas professores organizam sua ação didático-pedagógica convidamos a participar da pesquisa, assumindo a condição de colaboradores do estudo, 10 professores, de uma instituição de ensino superior privada, graduados em cursos de Fisioterapia e que estivessem atuando diretamente na sala de aula.

Após um levantamento junto à Plataforma Lattes, identificamos que, dos 10 fisioterapeutas professores, seis concluíram o mestrado em programas de Pós-Graduação em Ciências da Saúde; um professor é mestre e doutor em Educação em Ciências e três possuem título de especialista.

Optamos pelo conversar, que é um fluir na convivência, no entrelaçamento do linguagear e do emocionar (MATURANA H, 2014), como estratégia para conhecer os saberes e conhecimentos pedagógicos dos fisioterapeutas, que atuam como professores. O conversar ocorreu de forma individual e envolveu temas como o tempo de trabalho, a formação acadêmica, a decisão pela docência, práticas e técnicas utilizadas em sala de aula, recursos e avaliações do desempenho dos alunos que poderiam nos auxiliar a compreender o problema do estudo.

Aos colaboradores apresentamos os objetivos do estudo e solicitamos que assinassem o Termo de Consentimento Livre e Esclarecido. A conversa foi gravada, com autorização dos mesmos, e transcrita para posterior análise.

A amostra foi intencional e não probabilística, baseada nas preocupações éticas e metodológicas discutidas nas Diretrizes e Normas Regulamentadoras da Pesquisa Envolvendo Seres Humanos (Resolução 466/2012). O estudo foi autorizado pelo Comitê de Ética em Pesquisas na área da Saúde da Universidade Federal do Rio Grande - FURG, sob o número 170/15, e pela direção da faculdade em que a pesquisa ocorreu.

A análise do conversar foi desenvolvida com a técnica do Discurso do Sujeito Coletivo (DSC), de Lefèvre F e Lefèvre AM (2005), para quem o sujeito coletivo é uma técnica que se propõe a resgatar o pensamento coletivo, ou seja, investigar o que um grupo de pessoas pensam sobre um determinado tema. A proposta do DSC é romper com a lógica quantitativo-classificatória e visa a resgatar os discursos como signo de conhecimento dos próprios discursos. Esse pensar produz como resultado um discurso, que é o modo como as pessoas, como seres sociais, se expressam na linguagem e, apesar de envolver várias pessoas falando, não se trata de um "nós", mas de um "eu" coletivizado (LEFÈVRE F e LEFÈVRE AM, 2005).

\section{RESULTADOS E DISCUSSÃO}

A seguir, apresentamos os discursos: "O emocionar da docência" e a "Prática da docência", e fazemos sua discussão permeada pelo conversar teórico-reflexivo com baseados em autores como Maturana $\mathrm{H}$, Varela, Tardif M e Shulman L.

\section{A emoção de ser professor}

Nesse discurso os fisioterapeutas se mostram e nos mostram como se tornaram professores e o significado e sentido que expressam para a docência. 
Vivenciar a sala de aula era mais um desafio para mim, eu precisava saber se era isso que eu queria fazer. Vim cheio de ideias, com "sangue no olho" para ser professor. Eu acreditava que ia dar tudo super certo e na realidade foi bem chocante. Depois que eu comecei, resolvi que eu queria fazer, mas precisava me preparar melhor. Minha emoção de dar aula para uma turma é diferente da emoção de dar aula para outra turma. Eu penso que se eu me emociono com o que é ditto por alguém, eu vou prestar a atenção, vou me interessar. O que dá para perceber é que o nosso aluno chega na graduação muito mecanizado, resistente às mudanças. É mais cômodo fica no lugar comum. O novo, às vezes, assusta e, por isso, preferem uma aula mais passiva assistindo a apresentação do professor. Aquele aluno que não consegue estabelecer um emocionar nas relações corporais se trava, ele prefere nem estar presente.

\section{DSC 1 - 0 emocionar da docência}

Ensinar para Tardif M (2014) "é mobilizar uma ampla variedade de saberes que necessitam de reformulação, readaptação para transformarem-se pelo e para o trabalho". Ao afirmarem: "depois que eu comecei, resolvi que eu queria fazer, mas precisava me preparar melhor", os fisioterapeutas professores fazem emergir um mundo de significados e de sentidos para o exercício de outra profissão para a qual percebem não ter preparo.

Ao serem defrontados com a possibilidade da docência como profissão, os fisioterapeutas percebem que precisam buscar o que Ihes falta ou não possuem (ALMEIDA MI, et al., 2019). Entendem a necessidade de encontrar nos cursos de formação complementar uma nova articulação e um novo equilíbrio "entre os conhecimentos produzidos pelas universidades a respeito do ensino e os saberes desenvolvidos pelos professores em suas práticas cotidianas" (TARDIF M, 2014).

A emoção do agir em determinado momento do viver em um domínio operacional é o que define o modo particular como agimos nesse domínio de ações. Ou seja, devemos estar atentos à emoção que emerge nas atividades humanas para compreeender e aprender o que pretendem (MATURANA H, 2001). Assim, a emoção inicial dos professores de fisioterapia, na convivência cotidiana, se transforma.

Minha emoção de dar aula para uma turma é diferente da emoção de dar aula para outra turma. Eu penso que se eu me emociono com o que é ditto por alguém, eu vou prestar a atenção, vou me interessar (DSC1).

Para Maturana H (2002), criar um espaço reflexivo comum entre o linguajear e o emocionar, é dupla tarefa do professor. Assim, quando o coletivo expressa que "aquele aluno que não consegue estabelecer um emocionar nas relações corporais se trava, ele prefere nem estar presente", manifesta que nem todos os alunos estão no mesmo domínio consensual de ações.

Mas, o que podem fazer os professores para que seus estudantes se situem em um domínio de ações e emoções que lhes permitam estar abertos ao que não sabem? O DSC1 relata que os estudantes chegam à universidade fechados para mudanças ou inovações da sala de aula. Querem que os professores realizem as práticas pedagógicas conhecidas por eles, ou seja, querem receber do professor as bases conceituais e procedimentais da profissão, sem que seja necessário seu envolvimento nesse aprender (GOMEZCARRASCO C, et al., 2019). O fragmento que apresentamos, a seguir, mostra o desconforto do professor frente a passividade do aluno.

O que dá para perceber é que o nosso aluno chega na graduação muito mecanizado, resistente às mudanças. É mais cômodo ficar no lugar comum. $O$ novo, às vezes, assusta e, por isso, preferem uma aula mais passiva assistindo a apresentação do professor (DSC1).

O DSC1 nos permite afirmar que os estudantes chegam na graduação com as marcas de uma educação em que o professor é quem sabe, e o aluno é quem precisa aprender. 
Vivenciar a sala de aula, era mais um desafio para mim, eu precisava saber se era isso que eu queria fazer. Vim cheio de ideias, com "sangue no olho" para ser professor. Eu acreditava que ia dar tudo super certo e na realidade foi bem chocante (DSC1).

A reflexão sobre á ação docente exige dos professores uma grande disponibilidade afetiva e uma capacidade de discernir suas reações interiores, muitas vezes, portadoras de certezas sobre os fundamentos de sua ação. É no cotidiano com os alunos que o professor se depara com o conhecimento de si e com o conhecimento de suas próprias emoções e valores (BACKES VMS, et al., 2019).

Conforme Maturana H (2014) o conhecimento obriga-nos a uma atitude de permanente vigília contra a tentação da certeza, a reconhecer que nossas certezas não são provas da verdade, "como se o mundo que cada um vê fosse o mundo e não um mundo que construímos juntamente com os outros".

\section{A docência como profissão}

No segundo discurso coletivo, a experiência que atravessa cada indivíduo no exercício da docência acarreta um sentimento de profissionalismo adquirido por saberes experienciais considerados, pelos próprios professores, como a base do saber-ensinar (BORN BB, et al., 2019).

O aluno tem essa necessidade de enxergar, de ver a coisa, de ficar no concreto. Só assim o aluno diz que faz sentido. Ele se sente muito mais interessado com um caso clínico que exemplifique aquilo que está sendo abordado na teoria. Eu dou a minha aula conforme a turma, se eu vou preparado para falar de um assunto, mas a turma se mostra interessada em outra coisa, já mudo tudo. Sinto falta de outros saberes, por exemplo, de didática. Dizem que a aula tem que ser dinâmica, só que eu não sei como abordar sem ser técnico. Nossa proposta da aprendizagem tem que instigar o aluno, despertar a vontade de compreender aquela teoria, de ir além do que é dado na sala de aula, para compreender o que ele está vivenciando na prática e a gente vai aprendendo também com essas situações do dia a dia de sala de aula.

\section{DSC 2 - A prática da docência}

No discurso, o coletivo indica que as experiências profissionais são indispensáveis para dar sentido aos conteúdos teóricos que apresentam mas que a capacidade de improvisação faz parte do fazer docente como mostra o excerto a seguir:

Eu dou a minha aula conforme a turma, se eu vou preparado para falar de um assunto, mas a turma se mostra interessada em outra coisa, já mudo tudo (DSC2).

Para Tardif M (2014), são "essas múltiplas articulações entre a prática docente e os saberes que fazem dos professores um grupo social e profissional cuja existência depende, em grande parte, de sua capacidade de dominar, integrar e mobilizar tais saberes enquanto condições para sua prática".

Nóvoa A, et al. (2003) diz que um dos principais capítulos da história da profissão docente se baseia na relação entre os próprios professores e seus saberes. Questiona se "os professores são portadores (e produtores) de um saber próprio ou são apenas transmissores (e reprodutores) de um saber alheio?

A rede de conversação dos professores é produtora de percursos coletivos e singulares (RODRIGUES SC, 2007).

A autora afirma que os professores vivem á formação como uma experiência individual ao enxergarem o que fazem e o que querem, sem perceber que o que fazem no coletivo é o que os produz.

Nossa proposta da aprendizagem tem que instigar o aluno, despertar a vontade de compreender aquela teoria, de ir além do que é dado na sala de aula, para compreender o que ele está vivenciando na prática e a gente vai aprendendo também com essas situações do dia-a-dia de sala de aula (DSC2). 
O que esses profissionais afirmam corrobora o pensamento de Tardif $M(2014)$, pois os saberes desses profissionais são saberes da ação ou saberes do trabalho e no trabalho. Shulman $L(1986 ; 1996)$ aponta em seus estudos que o conhecimento amplo do que se deseja ensinar tem íntima relação com o trabalho pedagógico que é desenvolvido na sala de aula.

O DSC2 mostra como os conhecimentos, habilidades, competências e formas de saber-fazer dos professores de fisioterapia com relação ao conhecimento específico são construídos. Evidencia, porém, um sentimento de ausência de conhecimentos relativos à formação pedagógica (DE CONT M, 2018).

Sinto falta de outros saberes, por exemplo, de didática. Dizem que a aula tem que ser dinâmica, só que eu não sei como abordar sem ser técnico (DSC2).

Tardif M e Lessard C (2014), consideram que "ensinar não é tanto fazer alguma coisa, mas fazer com alguém alguma coisa significativa". Chamam de pedagogia "o conjunto de meios utilizados pelos professores para chegar a seus fins nas atividades de trabalho com os alunos." (TARDIF M e LESSARD C, 2014).

Para Shulman L (1986), o professor necessita compreender formas de apresentar um conceito para os alunos, maneiras de comunicar o conteúdo. Ressalta que o professor necessita desenvolver um raciocínio pedagógico.

Como parte do raciocínio pedagógico, a "compreensão" do que será ensinado precisa ir além de um conhecimento pessoal da matéria por parte do professor (MENEGAZ JC, et al., 2018). De acordo com Shulman L (1986), é necessário possuir um conhecimento que lhes permita criar condições para que seus alunos aprendam, criando condições que levem em consideração diferentes habilidades, conhecimentos prévios e estilos de aprendizagem de seus alunos.

O termo "transformação" é apresentado no sentido de designar o comportamento do professor ao se mover na própria compreensão da matéria a ser ensinada por narrativas, exemplos ou associações prováveis que possibilitem a compreensão por parte dos alunos. Isso consiste na essência do raciocínio pedagógico (ALMEIDA PCA, et al., 2019).

O excerto a seguir, é um discurso que exemplifica como os professores promovem o imbricamento da teoria com a prática.

[...] o aluno tem essa necessidade de enxergar, de ver a coisa, de ficar no concreto. Só assim o aluno diz que faz sentido. Ele se sente muito mais interessado com um caso clínico que exemplifique aquilo que está sendo abordado na teoria (DSC2).

Outro componente da base que forma o raciocínio pedagógico, segundo Shulman L (1986), é a "instrução" através da qual é observado o desempenho do professor envolvendo a organização e gestão da classe. Preparar o estudante para a profissão valoriza métodos ativos priorizando às experiências na interação dos alunos e professores (SILVA RRS e SCHERER RP, 2019).

A "avaliação", de acordo com Shulman L (1986), possibilita que as dúvidas e/ou equívocos dos alunos sejam reorganizados por vias formais de avaliação. Por isso que os fisioterapeutas professores expõem a necessidade de rever, cotidianamente, suas práticas de sala de aula.

A gente tem que avaliar a nossa forma de dar aula diariamente, ver o que deu certo e o que deu errado, como a turma se comporta com determinada metodologia, o que é bom para uma nem sempre é para a outra turma (DSC2).

O que leva o professor a uma outra etapa do raciocínio, chamada por Shulman L (1986) de "reflexão", que se trata de um processo reflexivo sobre a própria ação pedagógica. Desenvolver um portfolio reflexivo deve ser uma das ações desenvolvidas pelos docentes em saúde pois envolve um processo dinâmico de ensinar e aprender por meio do diálogo ativo entre os envolvidos na experiência (ZUKOWSKY-TAVARES C, et al., 2019). 
Finalmente Shulman L (1986) indica que, após todas essas etapas o professor passa a uma "nova compreensão" mais enriquecida dos propósitos, da matéria, do ensino, dos alunos, do próprio professor e de outros conhecimentos da base para o ensino. Educar deve ser um ato de amor, nunca neutro, sempre intencional (ZEA-BUSTAMANTE LE, 2019).

Percebemos pelo DSC2 que é na relação direta dessas etapas do raciocínio pedagógico, propostas por Shulman L (1986), que os professores destacam o estar com os alunos, uma posição ativa para á aprendizagem, e sentem a necessidade de conhecer estratégias e metodologias que os possibilitem explorar, o potencial dos envolvidos no processo de ensinar e de aprender.

\section{CONCLUSÃO}

Os discursos coletivos deram voz a um grupo específico de professores que contaram suas trajetórias de vida imbricadas com o desejo de estar na docência de forma efetiva ao aprender a fazer fazendo. Este desejo, que é comum ao coletivo que fala, demonstra que as relações e as interações recorrentes dentro de um espaço institucional, constitui a personalidade de cada profissional e que, ao mesmo tempo, é compartilhada e favorece, então, o surgimento da identidade do ser professor.

\section{REFERÊNCIAS}

1. ALMEIDA MI, et al. Socialização, profissionalização e trabalho de professores iniciantes. Educ. rev., 2019; 35(78): 187-206.

2. ALMEIDA PCA, et al. Categorias teóricas de shulman: uma revisão integrativa no domínio da educação profissional. Cafajeste. Pesqui., 2019; 49(174): 130-149.

3. BACKES VMS, et al. Lee shulman: contribuições para a investigação da formação docente em enfermagem e saúde. Texto contexto - enferm., 2017; 26(4): e1080017.

4. BORN BB, et al. Profissionalismo docente e estratégias para o seu fortalecimento: entrevista com Lee Shulman. Educ. Pesqui., 2019; 45: e201945002003.

5. DE CONTI M. Teoría del conocimiento pedagógico. Pedagogía y Saberes, 2018; 49: 177-188.

6. GOMEZ-CARRASCO C, et al. Educação histórica e competências educativas. Educ. rev., 2019; 35(74): $145-171$.

7. LEFÈVRE F e LEFÈVRE AM. O discurso do sujeito coletivo: um novo enfoque em pesquisa qualitativa (desdobramentos). Caxias do Sul: EDUCS, 2005; 256.

8. MATURANA H. Transformación en la Convivencia. Dolmen Ediciones S.A. Santiago, Chile, 2002; 283.

9. MATURANA H. Cognição, ciência e vida cotidiana. Belo Horizonte: Ed. UFMG, 2014; 219.

10. MATURANA H e VARELA F. A árvore do conhecimento: as bases biológicas da compreensão humana. 8ed. São Paulo: Palas Athenas, 2001; 288.

11. MENEGAZ JC, et al. Ação e raciocínio pedagógico de professoras de enfermagem: expressões em diferentes contextos educacionais. Texto contexto - enferm., 2018; 27(3), e2660016.

12. NÓVOA A, et al. Profissão professor. 2ed. Portugal: Ed. Porto, $2003 ; 192$.

13. RODRIGUES SC. Rede de conversação virtual: engendramento coletivo-singular na formação de professores. Tese (Doutorado) - Programa de Pós-Graduação em Informática na Educação, Universidade Federal do Rio Grande do Sul, Porto Alegre; 2007, 150p.

14. SILVA RRD e SCHERER RP. Por que precisamos da diferenciação pedagógica? Ensaio sobre a individualização e seus paradoxos. Rev. Bras. Educ., 2019; 24, e240041.

15. SHULMAN L. Those Who Understand: Knowledge Growth in Teaching. Educational Researcher, 1986; 2(15): 4-14.

16. SHULMAN L. Just in case: reflections on Learning from experience. In: COLBERT J, et al., The case for education: contemporary approaches for using methods. Massachusetts: Allyn\& Baron, 1996; 197-217.

17. TARDIF M. Saberes docentes e formação profissional. 17ed. Petrópolis: Vozes, 2014; 328p.

18. TARDIF M e LESSARD C. O trabalho docente: elementos para uma teoria da docência como profissão de interações humanas. 9ed. Petrópolis, RJ: Vozes, 2014; 320p.

19. ZEA-BUSTAMANTE LE. La educación para la salud y la educación popular, una relación posible y necesaria. Rev. Fac. Nac. Salud Pública, Medellín, 2019; 37(2): 61-66.

20. ZUKOWSKY-TAVARES $C$, et al. O portfólio e a construção de saberes docentes na pós-graduação em saúde. Pro-Posições, Campinas; 2019; 30, e2017018. 